\title{
OPEN Crystal structure and site-directed mutagenesis of circular bacteriocin plantacyclin B21AG reveals cationic and aromatic residues important for antimicrobial activity
}

Mian-Chee Gor ${ }^{1,2,9}$, Ben Vezina ${ }^{1,9}$, Róisín M. McMahon ${ }^{1}$, Gordon J. King ${ }^{3}$, Santosh Panjikar ${ }^{4,5}$, Bernd H. A. Rehm ${ }^{1,6}$, Jennifer L. Martin ${ }^{1,7}$ \& Andrew T. Smith ${ }^{1,8}$

Plantacyclin B21AG is a circular bacteriocin produced by Lactiplantibacillus plantarum B21 which displays antimicrobial activity against various Gram-positive bacteria including foodborne pathogens, Listeria monocytogenes and Clostridium perfringens. It is a 58 -amino acid cyclised antimicrobial peptide, with the $\mathrm{N}$ and $\mathrm{C}$ termini covalently linked together. The circular peptide backbone contributes to remarkable stability, conferring partial proteolytic resistance and structural integrity under a wide temperature and $\mathrm{pH}$ range. Here, we report the first crystal structure of a circular bacteriocin from a food grade Lactobacillus. The protein was crystallised using the hanging drop vapour diffusion method and the structure solved to a resolution of $1.8 \AA$. Sequence alignment against 18 previously characterised circular bacteriocins revealed the presence of conserved charged and aromatic residues. Alanine substitution mutagenesis validated the importance of these residues. Minimum inhibitory concentration analysis of these Ala mutants showed that $\mathrm{Phe}^{8} \mathrm{Ala}$ and $\mathrm{Trp}^{45} \mathrm{Ala}$ mutants displayed a 48- and 32-fold reduction in activity, compared to wild type. The Lys ${ }^{19} \mathrm{Ala}$ mutant displayed the weakest activity, with a 128 -fold reduction. These experiments demonstrate the relative importance of aromatic and cationic residues for the antimicrobial activity of plantacyclin B21AG and by extension, other circular bacteriocins sharing these evolutionarily conserved residues.

Bacteriocins are a group of ribosomally-synthesised antimicrobial peptides produced by both Gram-negative and Gram-positive bacteria. They generally confer antimicrobial activity against bacterial species and/or strains closely related to the bacteriocin producers. Many studies ${ }^{1-4}$ have suggested that these antimicrobial peptides have potential as natural food preservative. Bacteriocins have also been identified as possible next generation antibiotics to combat multiple-drug resistant pathogens ${ }^{3,5}$. In recent years, bacteriocins from Gram-positive bacteria, especially lactic acid bacteria (LAB) have attracted interest because they are generally regarded as safe (GRAS) for human consumption and are thought to have a broader antimicrobial spectrum than bacteriocins produced by Gram-negative bacteria ${ }^{6}$. Furthermore, Gram-positive bacteriocins are active against foodborne pathogens, making them important candidates for controlling food spoilage and pathogenic bacteria in the food and pharmaceutical industries ${ }^{6}$.

Bacteriocins produced by Gram-positive bacteria are divided into three main classes: class I-modified, class II- unmodified and class III-large, heat labile ${ }^{7}$. Of these, circular bacteriocins (class I) have gained attention due to their unique characteristics of high thermal and $\mathrm{pH}$ stability, as well as resistance to degradation by many proteolytic enzymes. The covalently linked $\mathrm{N}$ - and C-termini form a structurally distinct cyclic peptide

${ }^{1}$ Griffith Institute for Drug Discovery, Griffith University, Don Young Road, Nathan, QLD 4111, Australia. ${ }^{2}$ School of Science, RMIT University, Plenty Road, Bundoora, VIC 3083, Australia. ${ }^{3}$ Faculty of Science, University of Queensland, Brisbane, QLD, Australia. ${ }^{4}$ Australian Synchrotron, ANSTO, Clayton, VIC, Australia. ${ }^{5}$ Department of Molecular Biology and Biochemistry, Monash University, Melbourne, VIC 3800, Australia. ${ }^{6}$ Centre for Cell Factories and Biopolymers, Griffith Institute for Drug Discovery, Griffith University, Don Young Road, Nathan, QLD 4111, Australia. ${ }^{7}$ University of Wollongong, Northfields Avenue, Wollongong, NSW 2522, Australia. ${ }^{8}$ Griffith Sciences, Griffith University, Gold Coast, QLD 4222, Australia. ${ }^{9}$ These authors contributed equally: Mian-Chee Gor and Ben Vezina. ${ }^{\bowtie}$ email: andrew.smith@griffith.edu.au 
backbone $^{8}$. There are 20 circular bacteriocins reported in the literature to date, all are between 58 to 70 amino acids in length, corresponding to approximately 5.6 to 7.2 kilodalton $(\mathrm{kDa})$ in mass ${ }^{9,10}$. They are clustered into two families based on sequence similarity and biochemical characteristics. Family I bacteriocins are more cationic and have a higher isoelectric point $(\mathrm{pI} \sim 10)$ whereas members of family II are more hydrophobic and have a lower isoelectric point $(\mathrm{pI} \sim 5)^{8,11}$. Family I includes aureocyclicin $4185^{12}$, enterocin NKR-5-3B ${ }^{13}$, amylocyclicin ${ }^{14}$, amylocyclicin $\mathrm{CMW} 1^{15}$, enterocin AS- $48^{16}$, bacteriocin $21^{17}$ (identical to AS-48), carnocyclin $\mathrm{A}^{18}$, circularin $\mathrm{A}^{19}$, thermocin $458^{20}$, garvicin $\mathrm{ML}^{21}$, lactocyclicin $\mathrm{Q}^{22}$, leucocyclicin $\mathrm{Q}^{23}$, pumilarin ${ }^{9}$, uberolysin ${ }^{24}$ and cerecyclin ${ }^{25}$. These bacteriocins are found across a wide range of Gram-positive genera. Family II are generally found in Lactobacillus, Staphylococcus and Streptococcus species, and includes gassericin A/reutericin $6^{26}$, butyrivibriocin $A R 10^{27}$, acidocin $B^{28}$, paracyclicin ${ }^{29}$, plantaricyclin $A^{30}$ and plantacyclin $B 21 A^{31-33}$.

Until now, the only bacteriocin crystal structure reported was that of enterocin AS-48, which was solved by single isomorphous replacement with anomalous scattering (SIRAS) ${ }^{34}$. By comparison there are many Nuclear Magnetic Resonance (NMR) structures of bacteriocins ${ }^{35}$. For example, NMR solution structures have been reported for family I enterocin AS-48, carnocyclin A, enterocin NKR 5-3B and family II, acidocin B. Despite low sequence similarity, all the NMR and crystal structures demonstrate a conserved structural motif consisting of four to five $a$-helices encompassing a hydrophobic core, with the $\mathrm{C}$-teminus and $\mathrm{N}$-terminus ligation occurring within an $\alpha$-helix secondary structure ${ }^{11}$. The circular nature of these proteins contributes to remarkable stability against physical stresses ${ }^{8,36}$. The conformational and thermal stability of the circular enterocin AS-48 compared to its linear counterpart, $\mathrm{AS}_{10 / 11}$ obtained by limited proteolysis have been demonstrated previously ${ }^{37}$. For example, the linear $\mathrm{AS}_{10 / 11}$ has $35 \%$ lower $\alpha$-helical content compared with the native circular protein (measured by Far-UV circular dichroism (CD)). Linear $\mathrm{AS}_{10 / 11}$ is less compact and rigid compared to circular AS- $48^{38}$. Linear AS ${ }_{10 / 11}$ at pH 2.5 showed a low cooperativity of thermal unfolding and reduced stability compared to the circular AS-48, which was shown to unfold at $102^{\circ} \mathrm{C}^{39,40}$. The linear $\mathrm{AS}_{10 / 11}$ retained some antimicrobial activity although it was 300 times lower than the circular AS-48, suggesting that circularisation is not essential for bactericidal activity but more importantly for stabilisation of the three-dimensional structure of the bacteriocin ${ }^{37}$. Similarly, the linear version of AS-48, Trp70Ala mutant has just $18 \%$ helical structure compared to $72 \%$ in the circular AS- 48 , as measured by far-UV CD. Circular AS- 48 is extremely stable in comparison with its linear counterpart, with no sigmoidal transition observed between 25 and $95^{\circ} \mathrm{C}$, whereas linear Trp70Ala mutant had a melting temperature of $61^{\circ} \mathrm{C}^{41}$. These structurally stable circular bacteriocins and their mechanism of circularisation are of interest because of their biotechnological properties and applications. Proteins with new or improved features including enhanced stability could be generated through protein engineering, though this requires a deep understanding of bacteriocin structure-function relationships ${ }^{18,38}$.

We previously identified a circular bacteriocin plantacyclin B21AG from Lactiplantibacillus plantarum B21 (previously known as Lactobacillus plantarum) ${ }^{42}$. This family II circular bacteriocin has antimicrobial activity against foodborne pathogens including Listeria monocytogenes and Clostridium perfringens and other closely related Lactobacillus species ${ }^{31}$. We have also cloned the plantacyclin B21AG gene cluster into a plantacyclin B21AG-negative strain and used this system for its expression ${ }^{43}$. In the present study, we report the crystal structure of plantacyclin B21AG. Using this crystal structure, we identified by structural bioinformatics several conserved residues and showed via site-directed mutagenesis that these residues contribute to bactericidal function. Only one crystal structure has been reported for an enterocin AS-48, from bacteriocin family I which is evolutionarily quite distinct from family II circular bacteriocins ${ }^{10}$. Elucidation of the structure of plantacyclin B21AG could therefore provide new information in understanding the structure and function of these fascinating proteins. To the best of our knowledge, this is the first report of a crystal structure of a family II circular bacteriocin, and the first of a bacteriocin produced by a food grade LAB.

\section{Results and discussion}

Crystal structure of plantacyclin B21AG. Crystals of plantacyclin B21AG suitable for structure determination grew from hanging drop vapour diffusion using a well solution of $1.1 \mathrm{M}$ sodium malonate, $0.1 \mathrm{M}$ HEPES buffer $\mathrm{pH} 7.0$ and $0.5 \% \mathrm{v} / \mathrm{v}$ Jeffamine ED-2003. A crystal from these conditions diffracted to $1.8 \AA$ resolution and belonged to the space group $\mathrm{C} 222_{1}$. Crystallographic statistics for data collection/processing and refinement are shown in Table 1 . The crystal structure diffraction data were phased by molecular replacement using a theoretical $\alpha$-helix ( 8 residues long polyalanine) as a search model. The structure was refined to a final $\mathrm{R}_{\text {work }} / \mathrm{R}_{\text {free }}$ of $0.169 / 0.215$ at $1.8 \AA$ resolution. There are two independent molecules of plantacyclin B21AG in the asymmetric unit. The structures of these two molecules (Chain A and Chain B) are similar to each other, with a $\mathrm{C}^{\alpha}$ backbone root-mean-square deviation, RMSD of $0.56 \AA$ across $58 \mathrm{C}^{\alpha}$ atoms (Fig. 1a).

The structure of plantacyclin B21AG is characterised by four $\alpha$-helices, i.e. $\operatorname{Thr}^{14}-\operatorname{Ser}^{26}(\alpha 1), \mathrm{Leu}^{30}-\mathrm{Leu}^{38}(\alpha 2)$, $\mathrm{Gly}^{44}-\mathrm{Ala}^{52}(\alpha 3)$ and $\mathrm{Gly}^{54}-\mathrm{Phe}^{8}(\alpha 4)$. Helix $\alpha 1$ and helix $\alpha 4$ are linked covalently between Ile ${ }^{1}$ and Ala ${ }^{58}$ in the middle of helix $a 4$, creating a circular backbone (Fig. 1a). The four $\alpha$-helices in the crystal structure are connected by loops of 1 to 6 residues and enclose a hydrophobic core in a tightly folded globular arrangement (Fig. 1b). Together, the loops contain five surface exposed glycine residues i.e. Gly ${ }^{9}$, Gly $^{27}$, Gly ${ }^{39}$, Gly ${ }^{54}$ and Gly ${ }^{55}$. Glycines are often found in flexible loop regions as they do not contain a side chain, increasing the conformational flexibility (demonstrated by NMR solution structures of other circular bacteriocins) ${ }^{13,28,44}$. The hydrophobic core residues are $\mathrm{Ile}^{1}, \mathrm{Ile}^{4}, \mathrm{Ala}^{5}, \mathrm{Val}^{10}, \mathrm{Leu}^{12}, \mathrm{Ala}^{20}, \mathrm{Leu}^{24}, \mathrm{Leu}^{30}, \mathrm{Val}^{33}, \mathrm{Ala}^{34}, \mathrm{Ile}^{37}, \mathrm{Leu}^{38}, \mathrm{Val}^{40}, \mathrm{Leu}^{42}, \mathrm{Ala}^{46}, \mathrm{Ala}^{50}$ and $\mathrm{Ala}^{58}$. All of these residues have $<20 \%$ solvent exposure calculated based on GETAREA ${ }^{45}$. The second, third and fourth $\alpha$-helices are predominantly hydrophobic, with the linked amino acids at the $\mathrm{N}$ - and C-termini in helix $a 4$ buried in the core of the structure. In contrast, helix al is amphipathic, with hydrophilic residues ( $\operatorname{Thr}^{14}, \mathrm{Gln}^{18}$, $\mathrm{Ser}^{25}$ and $\mathrm{Ser}^{26}$ ) exposed at the surface of the protein. 


\begin{tabular}{|l|l|}
\hline \multicolumn{2}{|l|}{ Data collection } \\
\hline Space group & C222 1 \\
\hline Cell dimensions \\
\hline a, b, c $(\AA)$ & $44.13,93.17,49.49$ \\
\hline$\alpha, \beta, \gamma\left(^{\circ}\right)$ & $90,90,90$ \\
\hline Resolution $(\AA)$ & $46.58-1.80(1.84-1.80)^{\mathrm{a}}$ \\
\hline No. observations & 128,402 \\
\hline No. reflections & 9770 \\
\hline $\mathrm{R}_{\text {merge }}$ & $0.074(0.730)$ \\
\hline $\mathrm{R}_{\text {pim }}$ & $0.030(0.306)$ \\
\hline$I / \sigma I$ & $15.5(2.4)$ \\
\hline Completeness $(\%)$ & $99.8(96.7)$ \\
\hline Redundancy & $13.1(12.3)$ \\
\hline Refinement & \\
\hline Resolution $(\AA)$ & $46.58-1.80$ \\
\hline No. reflections & 9770 \\
\hline$R_{\text {work }} / R_{\text {free }}$ & $16.9 \% / 21.5 \%$ \\
\hline No. atoms & \\
\hline Protein & 802 \\
\hline Ligand/ion & 7 \\
\hline Water & 56 \\
\hline$B$-factor & 1.697 \\
\hline Protein & 26.1 \\
\hline Ligand/ion & 21.6 \\
\hline Water & 39.2 \\
\hline R.m.s. deviations & \\
\hline Bond lengths $(\AA)$ & 0.019 \\
\hline Bond angles $\left({ }^{\circ}\right)$ & \\
\hline
\end{tabular}

Table 1. Data collection and refinement statistics for the crystal structure of plantacyclin B21AG. The number of crystals used for structure determination and refinement is one. ${ }^{a}$ Highest resolution shell is shown in parenthesis.

The protein has an overall net charge of +3 at physiological $\mathrm{pH}$, with four cationic residues located in helix al ( Lys $^{15}$ and Lys $\left.{ }^{19}\right)$, helix $\alpha 4\left(\mathrm{Arg}^{6}\right)$ and the loop connecting al/a4 (His $\left.{ }^{11}\right)$, and one anionic residue located in helix al (Asp ${ }^{22}$ ) (Fig. 1c, upper panel). These charged residues are all displayed on the surface of the plantacyclin B21AG structure. The electrostatic potential surface map of plantacyclin B21AG reveals two cationic patches separated by an anionic strip (Fig. 1c, lower panel).

Structural comparisons of circular bacteriocins. To better understand the similarities and differences between known structures of circular bacteriocins, structural comparisons were performed between plantacyclin B21AG and other bacteriocin 3D structures elucidated to date, namely enterocin AS-48, carnocyclin A and enterocin NKR-5-3B (family I) and acidocin B (family II). We note that the acidocin B structure was determined using the bacteriocin embedded in SDS micelles ${ }^{28}$, whereas the other bacteriocin structures were determined under aqueous conditions $s^{13,34,44}$. These circular bacteriocins adopt a common 3D structure comprising four or five helices folded into a globular bundle enclosing a hydrophobic core ${ }^{11}$ (Fig. 2, left panel $)^{13,28,34,44}$. The orientation of the helices is similar within the members of each family, with the exception of enterocin AS- 48 which has five rather than four $\alpha$-helices. Notably, the circularisation point for all these bacteriocins is located within a helical structure which contains mostly hydrophobic residues ${ }^{36}$. Analysis of solvent exposed residues using GETAREA $^{45}$ reveals that the $\mathrm{N}$ - to $\mathrm{C}$-linkage of all these bacteriocins except the micelle embedded acidocin $\mathrm{B}$ is buried in the protein core (the ratio of side chain surface area to the average solvent-accessible surface area of the first and last amino acid, respectively is less than 20\%). Unlike saposins and saposin-like peptides which are stabilised by disulfide bonds between cysteine residues ${ }^{46}$, the bacteriocin helical fold appears to be stabilised by hydrophobic side chain interactions upon peptide circularisation ${ }^{44}$. Martin-Visscher et al. ${ }^{44}$ proposed that hydrophobic residues close to the $\mathrm{N}-\mathrm{C}$ linkage may play a role in the interaction between the linear peptide and the cyclisation enzyme, helping to bring the termini into close proximity for cyclisation to take place. A combination of circular backbone and hydrophobic core is thought to contribute to the stability of circular bacteriocins ${ }^{13}$.

Surface characteristics of circular bacteriocins. The molecular surface of the circular bacteriocins is amphipathic: one face of the molecule has cationic and anionic patches, and the other surface is uncharged 
Figure 1. Structural characteristics of plantacyclin B21AG. (a) Superposition of Chain A (magenta) and Chain $\mathrm{B}$ (yellow) of the crystal structure of plantacyclin B21AG. The blue dashed line indicates the N-to-C cyclisation point. (b) Hydrophobicity of plantacyclin B21AG. In this figure, the side chain atoms of hydrophobic residues (Ala, Ile, Leu, Phe, Pro, Gly, Trp and Val) are coloured in yellow. All other atoms of the same residues and all atoms of non-hydrophobic residues are shown in grey. Upper panel: Ribbon diagram illustrating the compact, hydrophobic core of plantacyclin B21AG. Hydrophobic side chains are drawn as sticks; Lower panel: Surface representation showing the solvent exposed hydrophobic side chains. (c) Ribbon diagram (upper panel) and electrostatic potential (lower panel) depicting amphipathicity of plantacyclin B21AG at physiological $\mathrm{pH}$. In the ribbon diagram, side chain atoms of the cationic and anionic residues are depicted in blue (Arg, Lys and His) and red (Asp), respectively. All other atoms of the same residues and all atoms of neutral residues are shown in grey. Electrostatic potential calculated by APBS function ${ }^{84}$ using PDB2PQR version 2.1.1 ${ }^{85}$ and surface map generated with Chimera $1.14^{86}$. Cationic, anionic and neutral residues are depicted in blue, red and white, respectively. Key residues are labelled with single amino acid codes and residue numbers.

or hydrophobic (Fig. 2, right panel). Generally, family I circular bacteriocins are more cationic than family II circular bacteriocins (Table 2). Noteworthy is the cationic region located close to the $\mathrm{N}$ - and C-ligation point ( $\alpha 1$ and $\alpha 4$ ). This cationic region is present in enterocin AS-48, carnocyclin A and enterocin NKR-5-3B. Eight lysine residues are located along the stretch of $\alpha 4$ and $\alpha 5$ in enterocin AS-48. Similarly, four lysine residues are located along $\alpha 3$ and $\alpha 4$ of carnocyclin A and enterocin NKR-5-3B (Fig. 2, right panel). The surface representation of the circular bacteriocins presented in Fig. 2 suggests that the charge distribution is conserved among circular bacteriocins ${ }^{13}$. The cationic surface patches are thought to be involved in an initial electrostatic interaction between the peptide and the negatively charged phospholipid bilayer of target cell membranes ${ }^{8,13,36}$. Binding of the cationic regions onto the target membrane may result in destabilisation of the membrane, potentially enabling peptide insertion ${ }^{4}$. However, it has also been demonstrated that electrostatic interaction alone is insufficient for antimicrobial activity. A 21-residue peptide fragment of enterocin AS-48 containing the cationic putative membrane interacting region exhibited competitive membrane binding ${ }^{47}$ but did not show antibacterial activity, suggesting that other physicochemical properties of the bacteriocins may be required for antimicrobial action.

Most of the bacteriocin anionic residues are located in close proximity to the cationic patches (Fig. 2, right panel). Whilst the role of anionic residues are generally overlooked in the context of circular bacteriocins, studies have shown that mutation of anionic residues in other classes of bacteriocins and/or antimicrobial peptides resulted in reduced bactericidal potency and altered target cell specificity ${ }^{48,49}$. Replacing aspartic acid at position 17 with the glutamic acid strongly enhanced the antimicrobial activity of the pediocin-like bacteriocin sakacin $\mathrm{P}$. This result suggests that the anionic residues interact in a structurally specific and restricted manner with a cationic region on the target cell or on the peptide itself ${ }^{50}$. Given that circular bacteriocins have been found to kill through disruption of proton motive force and pore formation ${ }^{51-53}$, it is likely that their conserved structural similarities will result in the placement of negative charges near the pore so as to facilitate pore selectivity and cation flow out of the target cell by reducing the electrostatic energy profile and increasing selectivity for divalent cations such as $\mathrm{Ca}^{2+54}$. These findings suggest that anionic residues are as important as cationic residues in terms of target specificity of the bacteriocins.

The Grand Average of Hydropathy (GRAVY) Index ${ }^{55}$ calculation reveals that family II circular bacteriocins are more hydrophobic than those in family I-except Carnocyclin A (Table 2). The hydrophobicity of plantacyclin $\mathrm{B} 21 \mathrm{AG}$ is evident in that it selectively dissolves into butanol fractions during purification. Some hydrophobic residues are exposed at the surface of the molecules (Fig. 2, right panel). The hydrophobicity of these peptides is thought to be crucial for creating pores in the bacterial membrane, especially for family II bacteriocins as they are less cationic ${ }^{28,46}$ (Table 2). Permeation of the cell membrane by these peptides causes leakage of ions, dissipation of membrane potential and eventually cell death ${ }^{8}$. The molecular mode of action of enterocin AS-48 has been widely studied and is the best understood of the circular bacteriocins. A model has been proposed ${ }^{34}$ such that the peptide in the form of a water-soluble dimer approaches the membrane surface of target bacteria through electrostatic interaction. Upon membrane interaction, each protomer within the water-soluble dimer rotates $90^{\circ}$ and rearranges such that the hydrophobic helices become solvent accessible. The transition of AS- 48 from water-soluble dimer to membrane-bound dimer allows the bacteriocin to insert into the bacterial membrane. This insertion alters the membrane potential, causing pore formation and cell leakage ${ }^{34,47,52}$. Collectively, these studies $^{34,47,52}$ have shown that cationic patches and hydrophobic patches play an important role in the mechanism of action of bacteriocins.

Structural alignment of circular bacteriocins. Structural alignment using the align function in $\mathrm{PyMOL}^{56}$ revealed that the three-dimensional structure of family II plantacyclin B21AG aligned well with family I enterocin NKR5-3B, with a r.m.s.d of $2.47 \AA$ across $30 \mathrm{C}^{\alpha}$ atoms. For both structures, the helices $\alpha 1, \alpha 2$ and $\alpha 4$ are similar in length and align in parallel in a similar orientation. $\alpha 3$ of enterocin NKR5-3B is twice the length of a 3 of plantacyclin B21AG but is oriented similarly (Fig. 3). The alignment of plantacyclin B21AG with enterocin NKR5-3B suggests that family I and family II bacteriocins could share a conserved three-dimensional structure with a very similar core fold, despite low sequence identity (15.6\%) (Fig. 4). In contrast, there is poor structural alignment between plantacyclin B21AG and enterocin AS-48 with r.m.s.d of $4.54 \AA$ across $45 \mathrm{C}^{\alpha}$ atoms (Fig. 3) (sequence identity $11.4 \%$, Fig. 4). AS-48 also has a longer sequence than plantacyclin B21AG (70 residues compared with 58) and forms five $a$-helices rather than four (Fig. 2). Similarly, plantacyclin B21AG and carnocyclin A do not align well, with r.m.s.d of $4.33 \AA$ across $45 \mathrm{C}^{\alpha}$ atoms (Fig. 3) (sequence identity 16.7\%, Fig. 4). 


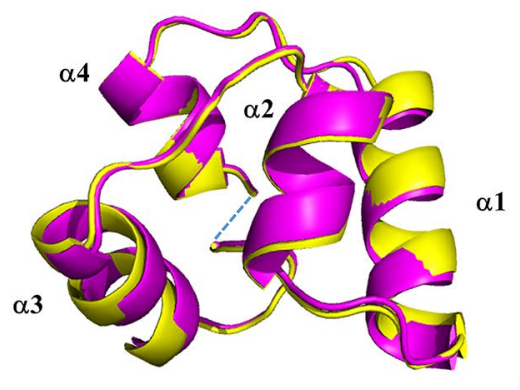

(a)
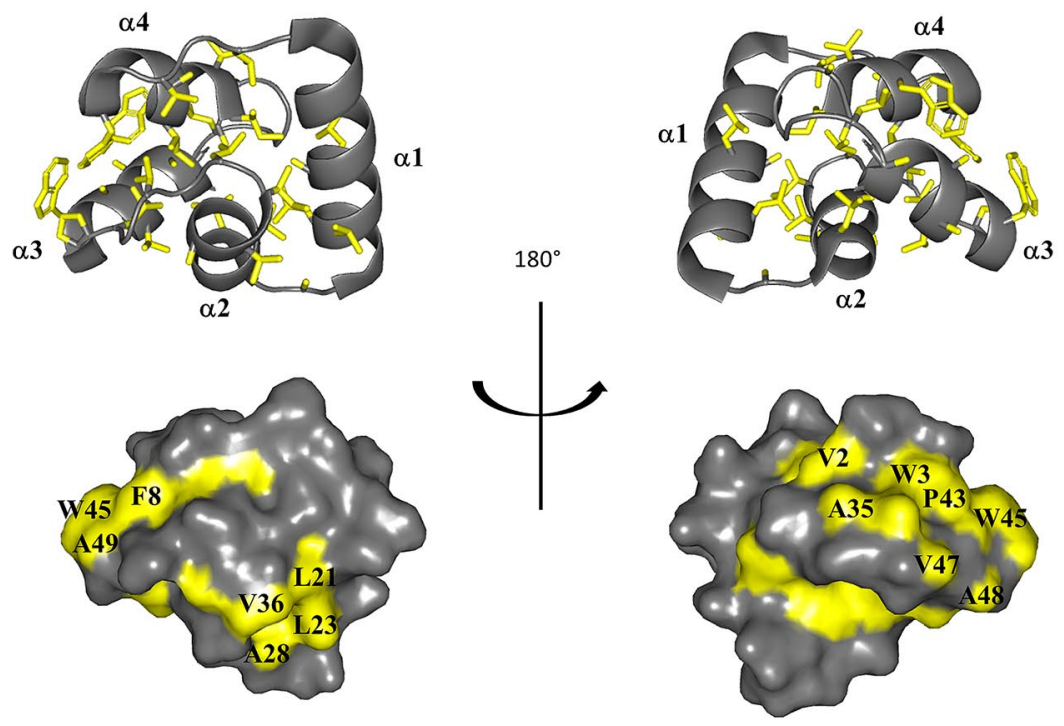

(b)
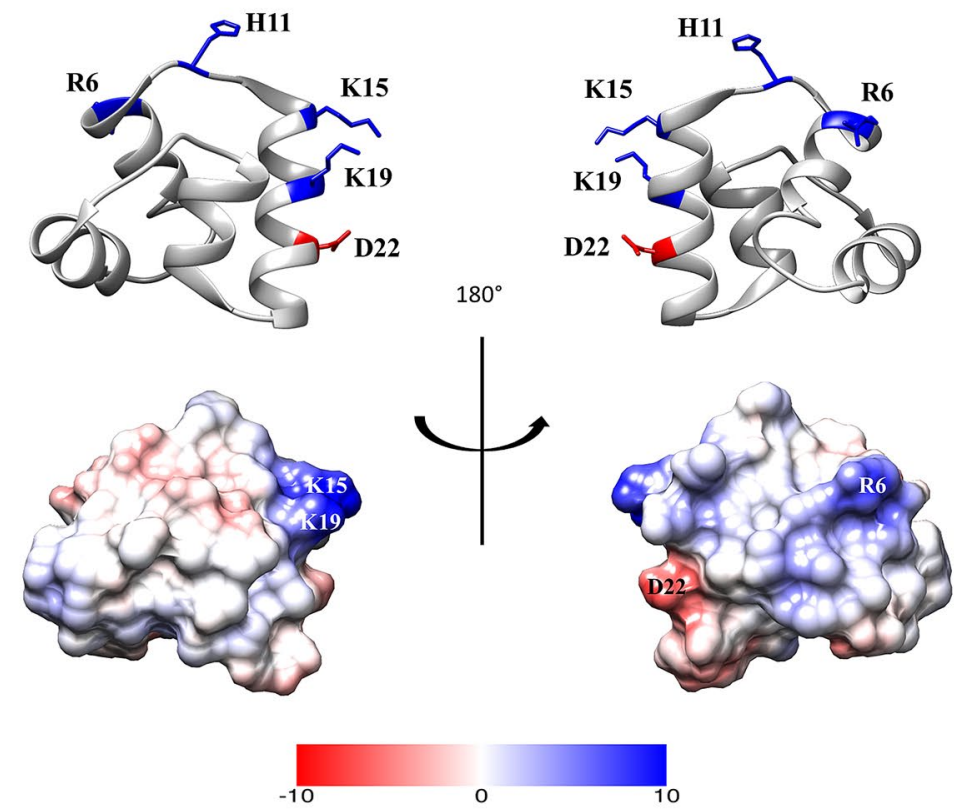

(c) 

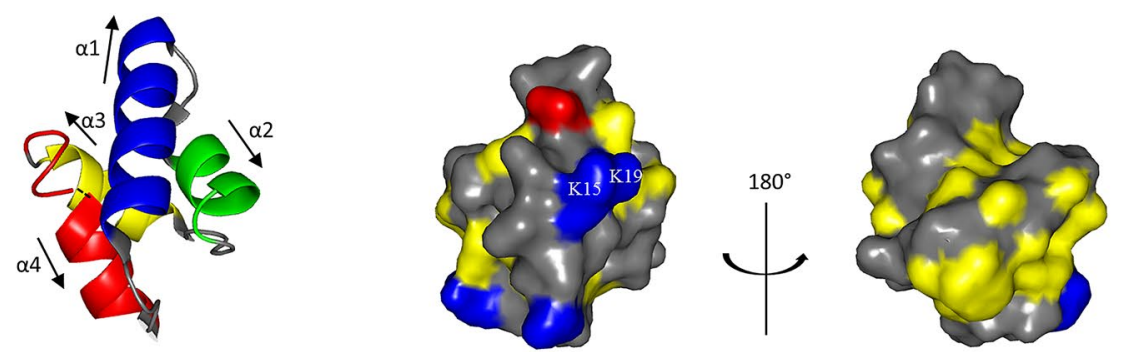

Plantacyclin B21AG (58aa)
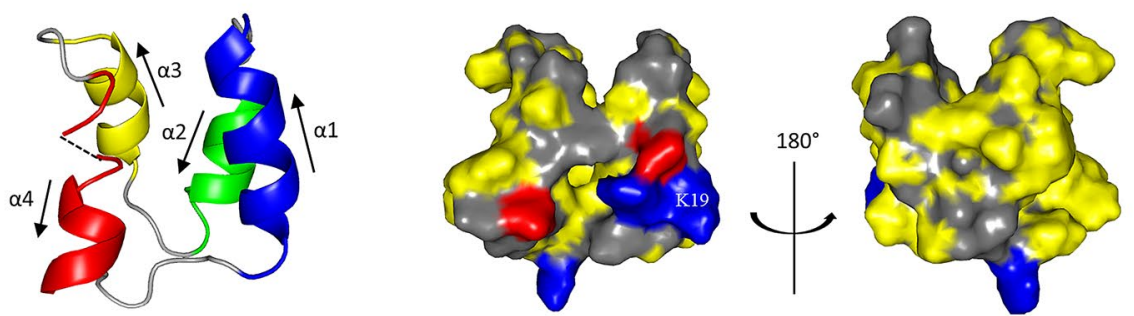

Acidocin B (58aa)
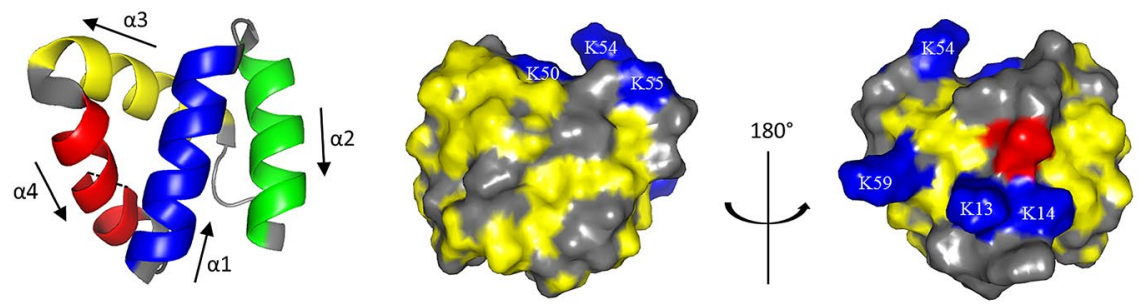

Enterocin NKR 5-3B (64aa)
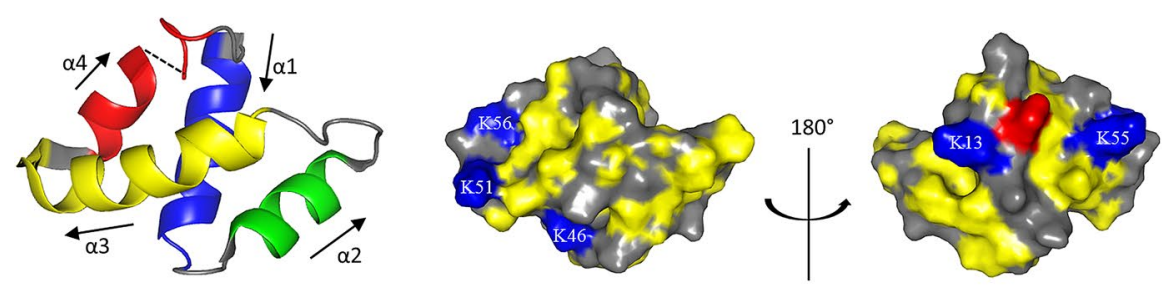

Carnocyclin A (60aa)
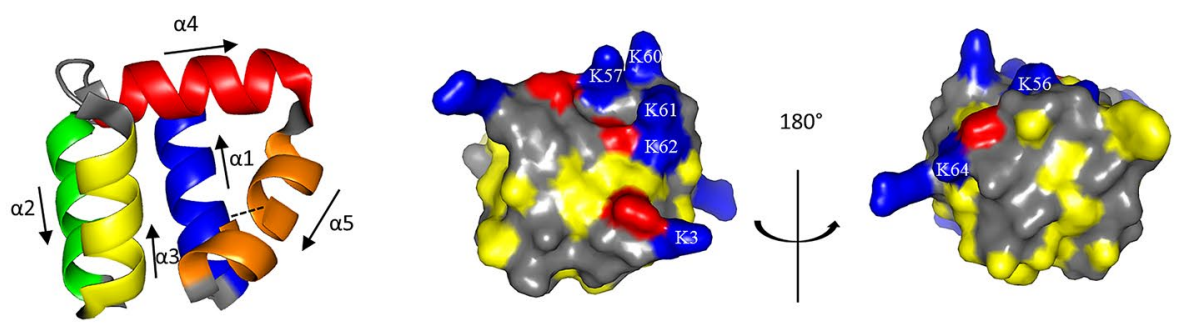

Enterocin AS-48 (70aa)

Figure 2. Three dimensional structural features of circular bacteriocins. Left panel: The helical orientation of the four/five $\alpha$-helices is shown as $\alpha 1$ (blue), $\alpha 2$ (green), $\alpha 3$ (yellow), $\alpha 4$ (red) and $\alpha 5$ (orange). The black arrows indicate the orientation of the a helices. The dotted black lines represent the linkage between the $\mathrm{N}$ and C-terminal. Right panel: Surface representation of the protein structures depicting side chain atoms of hydrophobic residues (yellow), cationic residues (blue), anionic residues (red) and polar residues (grey) at physiological $\mathrm{pH}$. Lysine residues are indicated with single amino acid codes and residue numbers. 


\begin{tabular}{|c|c|c|c|c|c|c|c|c|}
\hline Bacteriocin & Leader peptide (aa) & Mature peptide (aa) & MW (Da) & $\mathrm{pI}^{\mathrm{a}}$ & Net charge & $\begin{array}{l}\text { Hydrophobicity } \\
\text { (GRAVY Index) }^{\mathrm{b}}\end{array}$ & Producer organism & References \\
\hline \multicolumn{9}{|l|}{ Family I } \\
\hline Enterocin AS-48 & 35 & 70 & 7150 & 10.1 & +6 & 0.539 & $\begin{array}{l}\text { Enterococcus faecalis } \\
\text { AS-48 }\end{array}$ & Samyn, et al. ${ }^{16}$ \\
\hline Carnocyclin A & 4 & 60 & 5862 & 10.0 & +4 & 1.058 & $\begin{array}{l}\text { Carnobacterium mal- } \\
\text { taromaticum UAL } 307\end{array}$ & Martin-Visscher, et al. ${ }^{18}$ \\
\hline Enterocin NKR-5-3B & 23 & 64 & 6317 & 9.9 & +5 & 0.953 & $\begin{array}{l}\text { Enterococcus faecium } \\
\text { NKR-5-3 }\end{array}$ & Himeno, et al. ${ }^{13}$ \\
\hline \multicolumn{9}{|l|}{ Family II } \\
\hline Plantacyclin B21AG & 33 & 58 & 5668 & 10.0 & +3 & 1.002 & $\begin{array}{l}\text { Lactiplantibacillus } \\
\text { plantarum } \mathrm{B} 21\end{array}$ & Golneshin, et al. ${ }^{31}$ \\
\hline Acidocin B & 33 & 58 & 5622 & 6.8 & +1 & 1.036 & $\begin{array}{l}\text { Lactobacillus acidophi- } \\
\text { lus M46 }\end{array}$ & Acedo, et al..$^{28}$ \\
\hline
\end{tabular}

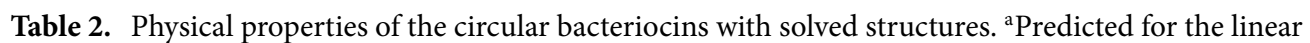
bacteriocin using ExPASy ProtParam Tool (https://web.expasy.org/cgi-bin/compute_pi/pi_tool). ${ }^{\text {} G r a n d ~}$ average of hydrophathy.

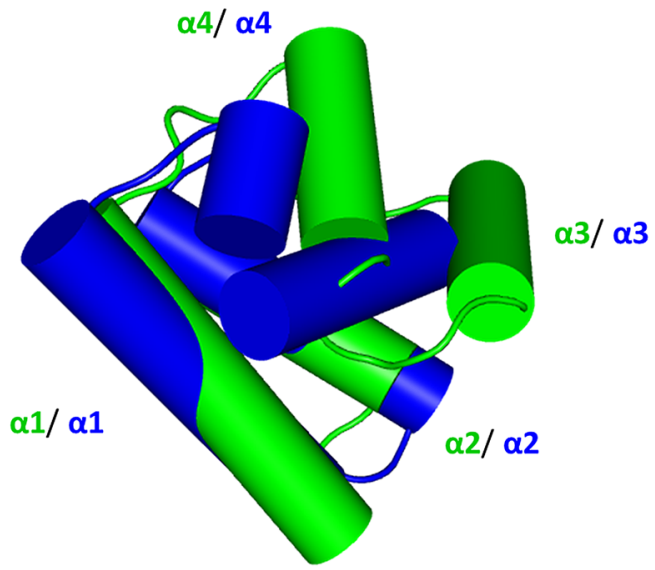

Plantacyclin B21AG and Enterocin NKR5-3B

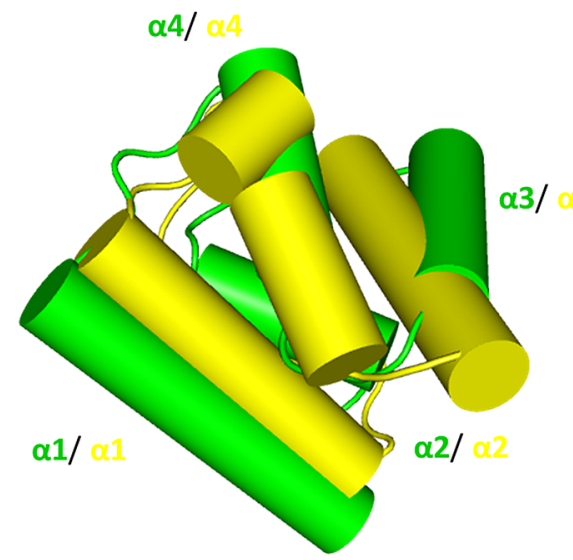

Plantacyclin B21AG and Carnocyclin A

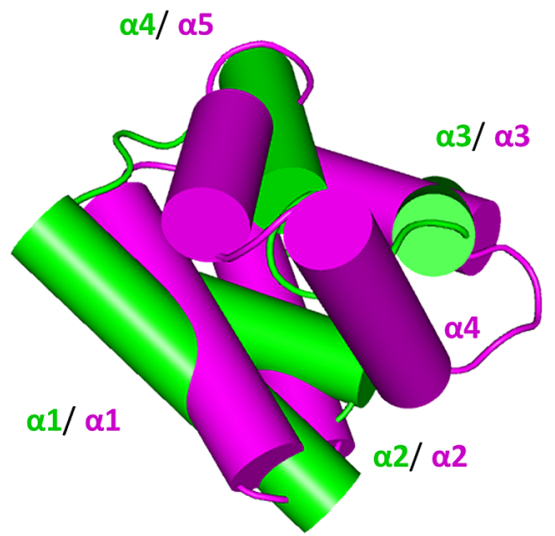

Plantacyclin B21AG and Enterocin AS-48

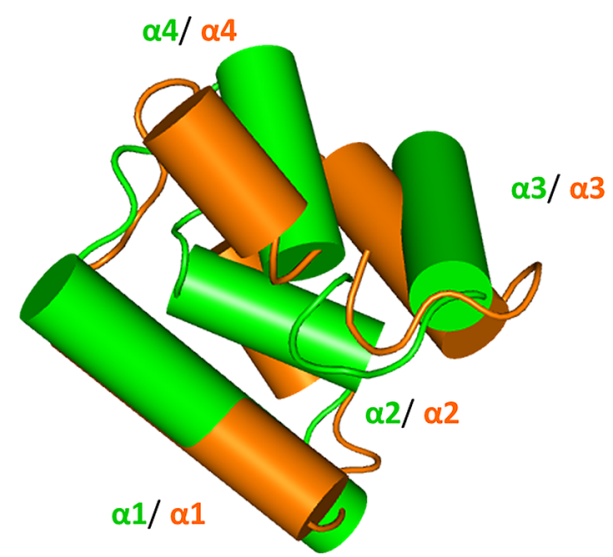

Plantacyclin B21AG and Acidocin B

Figure 3. Structural alignment of plantacyclin B21AG (green) with enterocin NKR-5-3B (blue), enterocin AS-48 (magenta), carnocyclin A (yellow) and acidocin B (orange). The helices are labelled accordingly using plantacyclin B21AG as reference. 

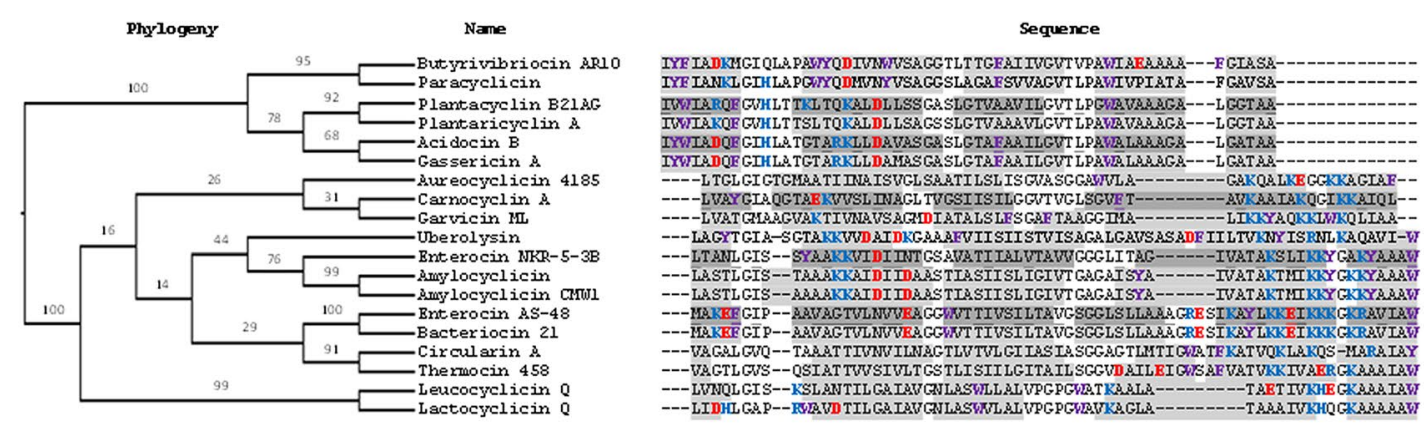

$\begin{array}{cc}\text { Resicues } & \boldsymbol{\alpha} \text {-helices } \\ 58 & 4 \\ 58 & 4 \\ 58 & 4 \\ 58 & 4 \\ 58 & 4 \\ 58 & 4 \\ 60 & 4 \\ 60 & 4 \\ 60 & 4 \\ 70 & 5 \\ 64 & 4 \\ 64 & 4 \\ 64 & 4 \\ 70 & 5 \\ 70 & 5 \\ 69 & 5 \\ 70 & 5 \\ 61 & 4 \\ 61 & 4\end{array}$

Figure 4. Phylogenetic tree showing the evolutionary relationship between the mature circular bacteriocin sequences, and their aligned sequences. Blue shows cationic residues. Red shows anionic residues. Purple shows aromatic residues. Dark grey highlighting shows $\alpha$-helices confirmed via structural information. Light grey highlighting shows $\alpha$-helices predicted by sequence alignment and secondary structure prediction. Underlining shows residues buried in protein core in experimentally determined structures. A. Sequence length of each protein is shown in "residues" column and number of known or predicted $\alpha$-helices is shown in column labelled a-helices.

Plantacyclin B21AG shares 65\% sequence identity with acidocin B (Fig. 4), and both belong to the circular bacteriocin family II. As indicated above, the NMR structure of acidocin B was determined in the presence of SDS micelles ${ }^{28}$. Not surprisingly, the structure of plantacyclin B21AG (determined in aqueous conditions) did not align well with that of acidocin B, giving a r.m.s.d. of $4.95 \AA$ across $57 \mathrm{C}^{\alpha}$ atoms (Fig. 3). Compared with aqueous conditions, SDS micelles may better mimic the bacterial membrane. Further elucidation of the crystal structure of plantacyclin B21AG in membrane-mimicking SDS micelle solvent system may provide a more direct comparison with the NMR solution structure of acidocin B and hence provide clues to the structural changes that occur in bacteriocin family II proteins upon membrane interaction.

Sequence analysis of circular bacteriocins. To extend the structural comparison, the sequence of plantacyclin B21AG was aligned against the sequences of 18 bacteriocins that have been previously experimentally characterised as circular. In each case, circularisation had been confirmed structurally or validated via independent experiments including electrospray ionization time-of-flight mass spectrometry (ESI-TOF MS) and peptide sequencing ${ }^{12-24,26-30}$. The details and sequences can be found in Supplementary Table S1. Amino acid sequence alignment of these circular bacteriocins shows two families within the class I circular bacteriocins (Fig. 4), which is consistent with recent phylogenetic analysis ${ }^{10}$. Secondary structure prediction suggests that these circular bacteriocins share considerable structural similarity despite sequence variation both within and between the two families. The results suggest that a sequence length of 69-70 residues gives a five $\alpha$-helical structure whereas a bacteriocin sequence with fewer than 69 residues gives a four helical structure. Jpred secondary structure prediction ${ }^{57}$ matched the experimentally determined secondary structure despite the large sequence diversity of the circular bacteriocins.

The position in the sequence of key amino acids such as charged, buried and aromatic residues appears to be conserved across the circular bacteriocin, which may hint at a key role for these residues in the protein antimicrobial activity. Specifically, the cationic residues located in helix $\alpha 3$ and $\alpha 4$ (helix $\alpha 4$ and $\alpha 5$ in the case of enterocin AS-48) in family I are predominantly but not exclusively lysine. In family II, histidine at position 11 and lysine at position 19 are highly conserved. These residues generally appear in polycationic clusters within the first, second, fourth/fifth $\alpha$-helices. Upon N- to C-termini ligation, these cationic residues are brought into close proximity.

Anionic residues in the circular bacteriocins are generally conserved, with almost all being found in close proximity to the membrane-interacting polycationic region and aromatic residues (Fig. 4). This matches the pattern observed with the structurally determined circular bacteriocins (Fig. 2, right panel). The N-C linkage point is buried in the hydrophobic core in the majority of experimentally determined structures of circular bacteriocins. In family I, the $\mathrm{N}$ - and C-terminal residues are generally conserved, sharing common characteristics. For example, the $\mathrm{N}$ terminus of family I utilises most commonly a leucine, then valine and methionine. These are all hydrophobic residues which are similar in size (117-149 Da). The $\mathrm{C}$ terminus consists of an aromatic residue, either a tryptophan, tyrosine or phenylalanine. Carnocyclin A and garvicin ML are exceptions to this pattern, having a leucine and alanine, respectively at the C-terminus. Instead, a conserved aromatic residue is present in the post-ligation site for carnocyclin A and in the pre-ligation site in garvicin ML. The termini of family II are also highly conserved in both sequence and residue characteristics. The $\mathrm{N}$-terminal residue is often isoleucine, or an aromatic residue, or a valine while the $\mathrm{C}$ terminus is an alanine in every case.

Aromatic residues are also highly conserved in family I and II and in addition to the C terminus of almost every family I sequence are found near the termini of predicted or confirmed a-helices. Tryptophan, phenylalanine and tyrosine that flank transmembrane-associated helices in other proteins are thought to facilitate membrane penetration $^{58,59}$. This may also be the case for the circular bacteriocin sequences (Fig. 4 ). The presence of conserved aromatic residues near $\alpha$-helices in circular bacteriocins may suggest they assist in cell membrane permeation and pore formation. For example, $\operatorname{Trp}^{24}$ is essential for the biological activity of AS-48, and is located in a hydrophobic region that interacts with the membrane ${ }^{60}$. Tryptophan has a preference for the interfacial 


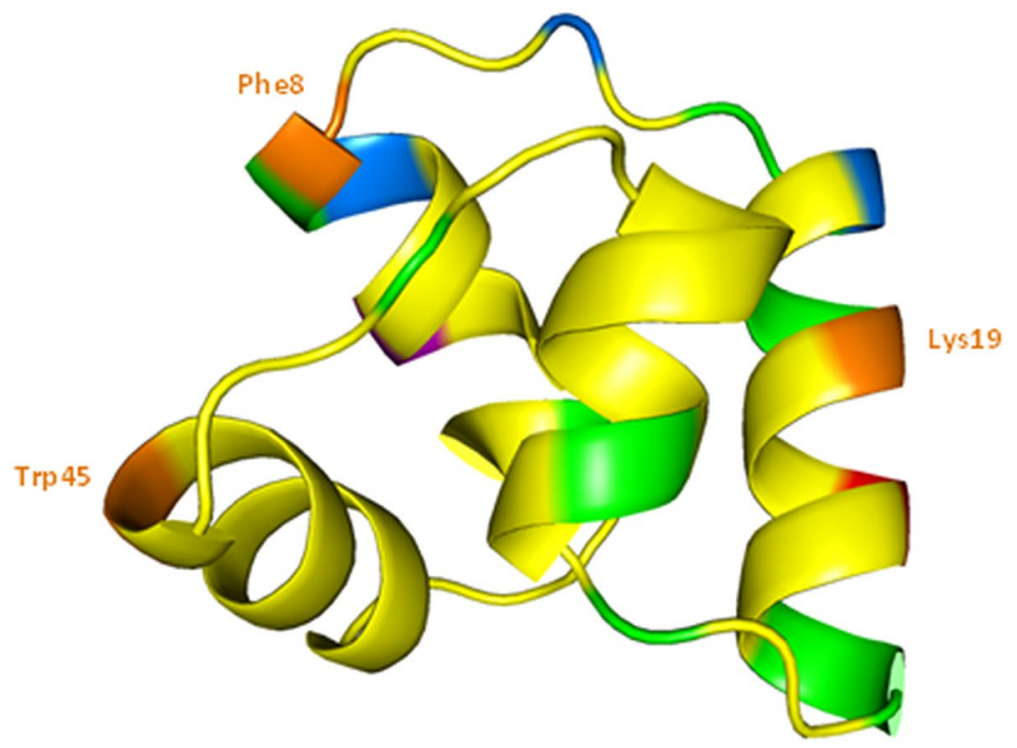

\section{IVWIAROFGVHLTTKLTOKALDLLSSGASLGTVAAVILGVTLPGKAVAAAGALGGTAA.}

Figure 5. $3 \mathrm{D}$ crystal structure of plantacyclin $\mathrm{B} 21 \mathrm{AG}$ mutagenesis location sites visualised in PyMOL with the corresponding amino acid sequence below. Orange shows the three residues $\left(\mathrm{Phe}^{8}, \mathrm{Lys}^{19}\right.$ and $\operatorname{Tr} \mathrm{p}^{45}$ ) nonsynonymously substituted with Ala. Colour indicates the positions of hydrophobic (yellow), polar (green), aromatic (purple), cationic (blue) and anionic (red) residues.

\begin{tabular}{|l|c|l|l|}
\hline L. plantarum WCFS1 sample & MIC $^{\mathbf{a}}(\mathbf{n g} / \boldsymbol{\mu L})$ & Fold-reduction of antimicrobial activity & $\begin{array}{l}\boldsymbol{p} \text { value compared to plantacyclin } \\
\text { B21AG-WT }\end{array}$ \\
\hline Plantacyclin B21AG-WT & $5.2 \pm 0.0$ & N/A & N/A \\
\hline Plantacyclin B21AG-Phe ${ }^{8} \mathrm{Ala}$ & $250 \pm 0.0$ & 48 & ${ }^{* *} p<0.01$ \\
\hline Plantacyclin B21AG-Lys ${ }^{19} \mathrm{Ala}$ & $666.7 \pm 0.0$ & 128 & ${ }^{*} p<0.01$ \\
\hline Plantacyclin B21AG-Tr ${ }^{45} \mathrm{Ala}$ & $166.7 \pm 0.0$ & 32 & ${ }^{*} p<0.01$ \\
\hline Untransformed (-) & $0 \pm 0.0$ & N/A & N/A \\
\hline 10 mM ammonium acetate (-) & $0 \pm 0.0$ & N/A & N/A \\
\hline
\end{tabular}

Table 3. Results of MIC antimicrobial assay against indicator strain L. plantarum A6. One-way ANOVA comparing every sample was performed, followed by a post-hoc Tukey honestly significant difference test, with $p$ values shown. MIC values are mean \pm STD of two biological replicates. ${ }^{a} M I C$ minimum inhibitory concentration, STD standard deviation, N/A no activity observed. Data are representative of two independent experiments, each in technical triplicate. ${ }^{\#}$ Plantacyclin B21AG-Lys ${ }^{19}$ Ala bacteriocin variant is not an intact species, accounting for the low but measurable killing activity as implied by the MIC value.

region of lipid bilayers and allows penetration of them ${ }^{61}$. $\operatorname{Tr}^{24}$ is essential for antimicrobial killing activity of gramicidin ${ }^{62}$, specifically for channel formation and conductance ${ }^{63}$ and altering energy profiles for ion permeation through long-range electrostatic interactions ${ }^{59}$. Tyrosine and phenylalanine can also have a similar effect ${ }^{64}$, with phenylalanine increasing membrane permeability of proteins ${ }^{65}$.

Mutagenesis of key residues in plantacyclin B21AG. To confirm the importance of specific residues, we performed site-directed mutagenesis on aromatic and cationic residues within the mature sequence of plantacyclin B21AG. These were non-synonymously substituted with alanine (Ala) to test their importance for antimicrobial activity. Figure 5 shows the location of the three altered residues, $\mathrm{Phe}^{8}$, Lys ${ }^{19}$ and $\operatorname{Trp}^{45}$. Other Ala substitution mutants ( $\mathrm{Arg}^{6}$ and $\mathrm{His}^{11}$ ) expression plasmids were constructed, however despite multiple attempts to transform the DNA into L. plantarum WCFS1, no transformants were recovered. This could be partly due to bacteriocin toxicity to recombinant host. In general, transformation into L. plantarum WCFS1 was inefficient, requiring many attempts for each construct.

The MIC assay results (Table 3) showed plantacyclin B21AG-WT had a value of at least $5.2 \mathrm{ng} / \mu \mathrm{L}$ against indicator strain L. plantarum A6, indicating potent antimicrobial activity against a strain closely related to the bacteriocin producer. By contrast the MIC values of each variant increased, indicating that the antimicrobial activity is reduced. The aromatic residues $\mathrm{Phe}^{8}$ and $\operatorname{Trp}^{45}$ appeared to be important for MIC activity; when replaced with Ala mutants the MIC activity was reduced by 48 and 32-fold, respectively. Mutation of aromatic 


\begin{tabular}{|l|l|l|l|}
\hline L. plantarum WCFS1 Sample & $\begin{array}{l}\text { Expected molecular weight if } \\
\text { circularised }\end{array}$ & MALDI-TOF results & $\begin{array}{l}\text { MALDI-TOF mass } \\
\text { minus expected } \\
\text { mass }\end{array}$ \\
\hline Plantacyclin B21AG-WT & 5667.7 & 5672.1 & 4.4 \\
\hline Plantacyclin B21AG-Phe ${ }^{8} \mathrm{Ala}$ & 5591.6 & 5590.4 & -1.2 \\
\hline Plantacyclin B21AG-Lys ${ }^{19} \mathrm{Ala}$ & 5610.6 & Not identified & N/A \\
\hline Plantacyclin B21AG-Trp ${ }^{45} \mathrm{Ala}$ & 5552.6 & 5550.9 & -1.7 \\
\hline Untransformed (-) & N/A & Not identified & N/A \\
\hline 10 mM ammonium acetate (-) & N/A & Not identified & N/A \\
\hline
\end{tabular}

Table 4. MALDI-TOF mass determination of plantacyclin B21AG-WT and mutants. Also shown is the expected size and mass differences. N/A not applicable.

residues in AS-48 also increased MIC across a range of indicator strains by a minimum of 28-fold for Listeria monocytogenes 4032 to 168 -fold for Enterococcus faecalis S- $47^{60}$, supporting the notion of a similar role for these residues, despite distinct phylogenetic divergence (Fig. 4).

Interestingly, replacement of Lys ${ }^{19}$ by Ala had the greatest impact on activity, reducing the antimicrobial activity by 128 -fold: $667 \mathrm{ng} / \mu \mathrm{L}$ was required to inhibit growth of the indicator strain as no turbidity was observed in the overnight culture, compared to $5.2 \mathrm{ng} / \mu \mathrm{L}$ for the wild type. The control we used was the untransformed $L$. plantarum WCFS1 with $10 \mathrm{mM}$ ammonium acetate, which demonstrated no MIC. This control confirms that the inhibitory activity was due to the respective bacteriocins alone. These MIC results identify an important functional role for $\mathrm{Phe}^{8}$, Trp ${ }^{45}$ and $\mathrm{Lys}^{19}$ three highly conserved residues identified in the sequence analysis of circular bacteriocins (Fig. 4). The MIC results are in agreement with previous computational inferences that conserved aromatic and cationic residues are important for antimicrobial activity ${ }^{10}$ of plantacyclin B21AG and by extension, other circular bacteriocins which share these features.

The observed masses of the wild type plantacyclin B21AG and its variants are listed in Table 4 and presented in Supplementary Figure S1. Notably, a mass was not identified for the plantacyclin B21AG Lys ${ }^{19}$ Ala mutant, despite evidence of antimicrobial activity and multiple attempts using fresh cultures and purifications. This mutant had a reduced antimicrobial activity compared with wild type (128-fold reduction). We suggest that substitution of Lys ${ }^{19}$ with Ala may result in reduced stability of plantacyclin B21AG. This may explain why it failed to produce a single discrete peak on MALDI-TOF. We hypothecate that degraded fragments may still be antimicrobially active, accounting for the killing assay. A possible explanation is that the $\mathrm{N}-\mathrm{C}$ terminal circularisation may be compromised in this mutant leading to increased instability ${ }^{30,39}$.

\section{Conclusions}

We report the crystal structure of a circular bacteriocin from the food grade Lactiplantibacillus plantarum B21. Structural comparison of plantacyclin B21AG and other circular bacteriocins confirms that these antimicrobial peptides share a highly conserved core fold and secondary structure composition, despite low sequence identity. In the structures solved in aqueous conditions, the $\mathrm{N}$ and $\mathrm{C}$ ligation point is buried in the hydrophobic core of the globular structure and positioned within an $\alpha$ helix. Sequence alignment of plantacyclin B21AG with other bacteriocins that have been characterised to be circular revealed highly conserved motifs including polycationic regions predicted to be surface exposed that could be involved in membrane interaction, binding and destabilisation. Proximally located anionic residues could be involved in pore selectivity that drives cation flow out of the target cell. Another common motif was the presence of conserved aromatic residues near the $\mathrm{N}$ and $\mathrm{C}$ terminal ends of helices $4-5$. These could be involved in membrane solubilisation, penetration and channel formation. Through multiple lines of evidence including sequence analysis, structure analysis, site-directed mutagenesis and antimicrobial activity, we demonstrated the importance of these evolutionarily conserved residues. In one case, substitution of residue Lys ${ }^{19}$ to Ala resulted in 128 -fold reduction of antimicrobial activity compared to the wild type plantacyclin B21AG. A problem encountered was the inefficient transformation efficiency of L. plantarum WCFS1 when transforming pTRKH2 backbone plasmids. Future work could focus on improving the efficiency by utilising different plasmid backbones and optimising the transformation protocol, to enable more rapid testing of other variants. Despite this limitation, we demonstrated that three aromatic and cationic residues have key functional roles in the antimicrobial activity of plantacyclin B21AG. Sequence and structure analysis suggest that several other conserved residues are likely to have key functional roles, these include $\mathrm{Arg}^{6}, \mathrm{His}^{11}$ and Asp ${ }^{22}$ as well as the $\mathrm{C}$ and $\mathrm{N}$ terminal residues. Sufficient information now exists for the systematic exploration of structure-function relationships, towards the understanding and creation of new microbial killing activities.

\section{Methods}

Expression and purification of plantacyclin B21AG. Lactiplantibacillus plantarum B21 was inoculated in $1 \mathrm{~L}$ of de Man, Rogosa \& Sharpe (MRS) broth using a $\%$ inoculum (v/v). The culture was incubated for $16-18 \mathrm{~h}$ at $30^{\circ} \mathrm{C}$ without shaking. The bacteriocin plantacyclin B21AG was purified from the culture supernatant through a four-step protocol, i.e. concentration of cell free supernatant, extraction with water-saturated butanol, desalting through PD10 and cation exchange Fast Protein Liquid Chromatography (FPLC). After overnight incubation, the culture was pelleted at $10,000 \times \mathrm{g}$ for $10 \mathrm{~min}$. The resulting cell free supernatant (CFS) was concentrated through a $10 \mathrm{kDa}$ polyethersulfone membrane disc using an Amicon Stirred Cell (Merck 
Millipore, Germany) to a final volume of $50 \mathrm{~mL}$. The concentrated CFS was then extracted twice with $1 / 2$ volume of water saturated butanol. The butanol fraction containing plantacyclin B21AG was dried under a fine stream of nitrogen to remove the butanol. The dried butanol fraction was then redissolved in $20 \mathrm{mM}$ of sodium phosphate buffer ( $\mathrm{pH}$ 6) and desalted using a NAP10 desalting column prepacked with Sephadex G-25 resin (GE healthcare, USA). Finally, the desalted protein fraction was purified using the Uno 66 prepacked monolith cation exchange column $(12 \times 53 \mathrm{~mm}, 6 \mathrm{~mL}$, Bio-Rad, USA) (Supplementary Figure S2). The eluted fraction containing purified bacteriocin was concentrated to $4.6 \mathrm{mg} / \mathrm{mL}$ in an Amicon centrifugal filter concentrator with a $3 \mathrm{kDa}$ cutoff membrane (Millipore) in buffer comprising $20 \mathrm{mM}$ sodium phosphate ( $\mathrm{pH}$ 6) for subsequent protein crystallisation.

Protein crystallisation and data collection. Protein crystallisation was performed at the UQ ROCX crystallisation facility at the Institute for Molecular Bioscience, University of Queensland. A JCSG-plus HT-96 commercial screen (Molecular Dimensions, USA) was used to screen for crystallisation conditions using the hanging drop vapour diffusion method. Briefly, plantacyclin B21AG was dissolved in water at a concentration of $2.3 \mathrm{mg} / \mathrm{mL}$. Each hanging drop comprised $100 \mathrm{~nL}$ of purified bacteriocin and $100 \mathrm{~nL}$ of crystallisation solution and were set up using a Mosquito crystallisation robot (TTP Labtech, UK) in a 96-well format. The crystallisation trays were incubated at $20^{\circ} \mathrm{C}$ in (and imaged using) a RockImager 1000 (Formulatrix, USA).

After $12 \mathrm{~h}$ incubation, a single crystal formed in condition F10 of JCSG screen containing 1.1 M sodium malonate, 0.1 M HEPES buffer $\mathrm{pH} 7.0$ and $0.5 \% \mathrm{v} / \mathrm{v}$ Jeffamine ED-2003. A single crystal was harvested after 13 days of incubation. X-ray diffraction experiments were performed at the micro-focus beamline (MX2) of the Australian Synchrotron ${ }^{66}$. Crystals were flash-cooled and stored in liquid nitrogen before transferring to a stream of nitrogen gas at $100 \mathrm{~K}$ at the beamline. X-ray diffraction data were collected at a wavelength of $0.9537 \AA$ using an EIGER-16 M detector at distance of $230.028 \mathrm{~mm}$ and with $0.1^{\circ}$ oscillation and $0.1 \mathrm{~s}$ exposure of $0 \%$ attenuated beam per frame. 3600 frames of the data set were collected in $36 \mathrm{~s}$. The data were processed and scaled using $\mathrm{XDS}^{67}$ and Aimless ${ }^{68}$, respectively.

Crystal structure determination and refinement. Attempts to solve the X-ray crystal structure of plantacyclin B21AG by molecular replacement (MR) using the NMR structure of acidocin B did not yield a solution. Instead, the phases for plantacyclin B21 AG crystal structure were solved by molecular replacement (MR) method with a short model helix structure of 8 amino acids (polyalanine) as a search model, using the program Phaser in the CCP4 suite ${ }^{69,70}$. The program placed six helices in an asymmetric unit with LLG of 393 . The six helical model was used in SHELXE ${ }^{71-73}$ for density modification and polyala model building. The polyala model (109 residues in two chain) resulting from SHELXE was provided to MR phasing protocol of Auto-Rickshaw ${ }^{74,75}$ server (https://www.embl-hamburg.de/Auto-Rickshaw) for phase improvement, model building and sequence docking. Within the software pipeline, MR was skipped and the partial model was refined in $\mathrm{CNS}^{76}$ for $\mathrm{B}$-factor and positional refinement. Further refinement in REFMAC5 ${ }^{77,78}$ resulted in R/Rfree of $38.7 \% / 40.1 \%$. Density modification was performed in PIRATE ${ }^{79}$ and the resulting phases were used in ARP/WARP ${ }^{80}$ for automated model building. The above density modification and model building procedure were repeated twice, which resulted in a model containing 112 residues with docked sequence in two chains. The last round of refinement (using REFMAC5) gave R/Rfree of $25.7 \% / 30.5 \%$. At this stage, the model was used for manual rebuilding and refinement. 56 water molecules were included where the $\mathrm{mFo}-\mathrm{nFc}$ difference electron density showed a peak above $3 \sigma$ and the modelled water made stereochemically reasonable hydrogen bonds. Final refinement was performed with REFMAC5. A Ramachandran plot showed that $99.1 \%$ of the residues were in the preferred regions and $0.9 \%$ were in the allowed regions. The quality and geometry of the final structure were evaluated and validated using wwPDB validation system ${ }^{81}$. Figures were prepared using PYMOL ${ }^{56}$. Data collection and refinement statistics are presented in Table 1. The final refined model has been deposited in the Protein Data Bank with the code 6WI6 using wwPDB OneDep system ${ }^{82}$.

Structural analysis. Superposition of Chain A and Chain B of Plantacyclin B21AG was performed using WinCoot 0.8.9. $2^{83}$. The percentage of solvent exposure of each amino acid residue was calculated using GETAREA 1.0 beta (https://curie.utmb.edu/getarea.html) ${ }^{45}$, a web service provided by the Sealy Center for Structural Biology at the University of Texas Medical Branch. The electrostatic potential surface map was calculated using the APBS functionality ${ }^{84}$ in the PDB2PQR web server (version 2.1.1) (https://nbcr-222.ucsd.edu/pdb2pqr_2.1.1/) ${ }^{85}$ and the figures generated using Chimera $1.14^{86}$. The isoelectric focusing point of the proteins was computed using the Compute pI/MW tool in ExPASy (https://web.expasy.org/compute_pi/). Structural alignment between circular bacteriocins was performed using the Align function in $\mathrm{PyMOL}^{56}$.

Circular bacteriocin sequence analysis. Plantacyclin B21AG sequence was aligned against sequences of bacteriocins previously characterised to be circular. The sequences were mined from NCBI database and aligned using Clustal Omega (https://www.ebi.ac.uk/Tools/msa/clustalo/) ${ }^{87}$. The alignment was manually edited to remove gaps for figure clarity and exported to fasta format, which was converted to phylip format using Sequence Conversion (https://sequenceconversion.bugaco.com/converter/biology/sequences/fasta_to_phyli p.php). This was used as input into RAxML (raxmlHPC-PTHREADS-SSE3 version 8.2.10) ${ }^{88}$ using the following parameters for $\mathrm{ML}+$ rapid bootstrap analysis with 100 replicates: $-\mathrm{T} 2$-f a $-\times 285-\mathrm{m}$ PROTGAMMABLOSUM62 -p 639 -N 100.

The bipartitions output file was used in FigTree version 1.4.4 (https://tree.bio.ed.ac.uk/software/figtree/) for viewing/manipulation. 


\begin{tabular}{|c|c|c|c|c|}
\hline DNA name & Size (bp) & Modification/sequence & Features & References \\
\hline \multicolumn{5}{|l|}{ Synthesised DNA } \\
\hline $\mathrm{Phe}^{8} \mathrm{Ala}$ & 998 & N/A & BamHI/PciI restriction sites & This study \\
\hline Lys $^{19} \mathrm{Ala}$ & 998 & N/A & BamHI/PciI restriction sites & This study \\
\hline Trp ${ }^{45} \mathrm{Ala}$ & 998 & N/A & BamHI/PciI restriction sites & This study \\
\hline \multicolumn{5}{|l|}{ Plasmids } \\
\hline pСусB21 & 10,126 & N/A & $\begin{array}{l}\text { Plantacyclin B21AG synthesis cluster, Em }{ }^{\mathrm{R}} \text {, E. coli and Lactobacillus } \\
\text { replication }\end{array}$ & Gor, et al. ${ }^{43}$ \\
\hline pCycB21-Phe ${ }^{8} \mathrm{Ala}$ & 10,126 & Phe ${ }^{8}$ Ala ligated to $\mathrm{pCycB21} \mathrm{BamHI/PciI}$ & $\begin{array}{l}\text { Plantacyclin B21AG synthesis cluster, Em }{ }^{\mathrm{R}} \text {, E. coli and Lactobacillus } \\
\text { replication }\end{array}$ & This study \\
\hline pCycB21-Lys ${ }^{19} \mathrm{Ala}$ & 10,126 & Lys ${ }^{19}$ Ala ligated to $\mathrm{pCycB21} \mathrm{BamHI/PciI}$ & $\begin{array}{l}\text { Plantacyclin B21AG synthesis cluster, Em }{ }^{\mathrm{R}} \text {, E. coli and Lactobacillus } \\
\text { replication }\end{array}$ & This study \\
\hline pCycB21-Trp ${ }^{45} \mathrm{Ala}$ & 10,126 & Trp ${ }^{45}$ Ala ligated to pCycB21 BamHI/PciI & $\begin{array}{l}\text { Plantacyclin B21AG synthesis cluster, Em }{ }^{\mathrm{R}} \text {, E. coli and Lactobacillus } \\
\text { replication }\end{array}$ & This study \\
\hline \multicolumn{5}{|l|}{ Primers } \\
\hline M13 F & 17 & GTAAAACGACGGCCAGT & Used in diagnostic PCR with B21AG_Seq R to produce 1167 bp product & Standard primer \\
\hline B21AG_Seq R & 31 & CAATAATTGTAATGACACGTACTAACATATC & Used in diagnostic PCR with M13 F to produce 1167 bp product & This study \\
\hline
\end{tabular}

Table 5. DNA and plasmids used in this study.

Jpred $4^{57}$ (https://www.compbio.dundee.ac.uk/jpred/, date accessed: 2/9/18) was used for prediction of secondary structures of sequences without confirmed structures. The Jnet prediction algorithm was initially run, then to determine the secondary structures around the $\mathrm{C}$ and $\mathrm{N}$ termini, protein sequences were rearranged, and run again.

Site-directed mutagenesis. Plasmid construct pCycB $21^{43}$ was used as a basis for mutagenesis studies. 998 bp inserts containing site-directed mutations were generated via DNA synthesis (Biomatik), flanked with $\mathrm{BamHI} / \mathrm{Pci}$ restriction sites and 6 base pair (bp) protection bases. These were subcloned into pCycB21, replacing the wild type (WT) sequence. The details of each construct are found in Table 5.

Transformation into plantacyclin B21AG-deficient strain. As previously shown, Lactiplantibacillus plantarum WCFS1 shares $99 \%$ genome identity to original plantacyclin B21AG producer L. plantarum B21 $1^{89}$. The generated constructs were transformed into Lactiplantibacillus plantarum WCFS1 (ATCC BAA-793) ${ }^{43}$ via electroporation ${ }^{90}$ with some alterations. Briefly, $0.1 \mathrm{~mL}$ of an overnight culture was inoculated into $5 \mathrm{~mL}$ MRS media (Oxoid) containing $1 \%$ glycine and $0.75 \mathrm{M}$ sorbitol. Cells were grown at $37^{\circ} \mathrm{C}$ until mid-exponential phase $\left(\mathrm{OD}_{600}\right.$ of $\left.1.5-3\right)$ then centrifuged at $4000 \times \mathrm{g}$ for $5 \mathrm{~min}$ at $4{ }^{\circ} \mathrm{C}$. From this point on, cells were kept on ice and centrifuged as above. Cells were then washed twice with a 10:1 volume of transformation solution containing $950 \mathrm{mM}$ sucrose and $3.5 \mathrm{mM} \mathrm{MgCl}_{2}$. Cells were resuspended in $80 \mu \mathrm{L}$ of transformation buffer and $500 \mathrm{ng}$ of plasmid DNA was added to cells. This mixture was then added to $0.2 \mathrm{~cm}$ cuvette (Bio-Rad) and electroporated with a Gene Pulser (Bio-Rad) with the following conditions: $2 \mathrm{kV}, 25 \mu \mathrm{F}$ and $400 \Omega$. If the time constant was $\geq 10$, another $500 \mathrm{ng}$ of DNA was added, and the electrical pulse repeated. $1 \mathrm{~mL}$ of MRS containing $100 \mathrm{mM} \mathrm{MgCl}$ and $0.5 \mathrm{M}$ sucrose was used to quickly rescue cells from cuvette. The mixture was added to $1.5 \mathrm{~mL}$ microtubes and cells were incubated at $37^{\circ} \mathrm{C}$ for $3 \mathrm{~h}$, then $200 \mu \mathrm{L}$ were spread onto MRS agar plates containing $15 \mu \mathrm{g} / \mathrm{mL}$ of erythromycin (Sigma-Aldrich). Plates were grown at $37^{\circ} \mathrm{C}$ for $48 \mathrm{~h}$ and colonies screened via erythromycin resistance phenotype and Polymerase Chain Reaction (PCR). Sanger sequencing was performed on the PCR products using both primers to confirm the transformants, at the Griffith University DNA Sequencing Facility, QLD, Australia.

PCR. PCR was performed using GoTaq Green Master Mix (Promega) as per manufacturer's instructions. Thermocycling conditions were as follows: Initial 2-min melting step of $95^{\circ} \mathrm{C}$, followed by 35 cycles of: $95^{\circ} \mathrm{C}$ for $15 \mathrm{~s}, 52^{\circ} \mathrm{C}$ for $15 \mathrm{~s}, 72^{\circ} \mathrm{C}$ for $1 \mathrm{~min} 20 \mathrm{~s}$. A final extension of $72^{\circ} \mathrm{C}$ for $5 \mathrm{~min}$ was performed.

Partial-purification of $L$. plantarum WCFS1-derived bacteriocins. After L. plantarum WCFS1 transformants had been confirmed, they were grown for $24 \mathrm{~h}$ in $100 \mathrm{~mL}$ MRS cultures containing $15 \mu \mathrm{g} / \mathrm{mL}$ erythromycin. Untransformed L. plantarum WCFS1 cells were also grown overnight in MRS without antibiotics to serve as a negative control. Cells were centrifuged at $8000 \times g$ for $10 \mathrm{~min}$, then supernatant concentrated to $2 \mathrm{~mL}$ using $3 \mathrm{kDa}$ Amicon Ultra-15 Centrifugal Filter Units (Merck). Supernatant was then washed 3 times with $15 \mathrm{~mL} 10 \mathrm{mM}$ ammonium acetate to remove residual erythromycin. Concentrated supernatant was then $\mathrm{n}$-butanol extracted as above and then removed in a rotary evaporator. The dried fraction was then resuspended in $10 \mathrm{mM}$ ammonium acetate. Concentration of the bacteriocin from the partial purification was calculated using the extinction coefficient ${ }^{91}$ and $280 \mathrm{~nm}$ absorbance value using the ProtParam calculator https://www. protparam.net/index.html. Concentration was also evaluated with a Bradford assay, using bovine serum albumin as a standard to increase confidence in values generated (data not shown). 
Mass analysis using MALDI-TOF MS. Samples were analysed in a buffer containing $10 \mathrm{mM}$ ammonium acetate with $0.1 \%$ formic acid. Analysis was performed on a ABSciex MALDI 5800 at the Mass Spectrometry Facility, University of Queensland, Centre for Clinical Research, QLD, Australia. A Bacterial Test Standard (Bruker) was used to calibrate the instrument. Partially purified supernatant from L. plantarum WCFS1 untransformed (-) was used as a negative control along with $10 \mathrm{mM}$ ammonium acetate with $0.1 \%$ formic acid.

Minimum inhibitory concentration assays of partially purified site-directed mutants. After partial-purification, the minimum inhibitory concentration (MIC) of the plantacyclin B21AG-WT and mutants were evaluated. WT refers to the bacteriocin produced by $L$. plantarum WCFS1 transformed with pCycB21 rather than native producer L. plantarum B21, herein this manuscript referred to as plantacyclin B21AG.

MIC assays were performed in clear 96 well plates (Greiner). $150 \mu \mathrm{L}$ MRS containing $3 \times 10^{5} \mathrm{CFU} / \mathrm{mL}$ of indicator strain L. plantarum A $6^{92,93}$ were added to wells. Partially purified bacteriocin samples were examined by making dilutions in $150 \mu \mathrm{L} 10 \mathrm{mM}$ ammonium acetate, then added to the wells. 1:2 serial dilutions of the bacteriocin were performed, evaluating each plantacyclin B21AG mutant from 1000 to $5.2 \mathrm{ng} / \mu \mathrm{L}$. Supernatant from L. plantarum WCFS1 untransformed $(-)$ and $10 \mathrm{mM}$ ammonium acetate without bacteriocin were used as a bacteriocin negative controls. $10 \mathrm{mM}$ ammonium acetate without bacteriocin or indicator strain was used as a blanking control. Plates were incubated at $37^{\circ} \mathrm{C}$ for $24 \mathrm{~h}$ and read using a Synergy 2 (BioTek) plate reader at $600 \mathrm{~nm}$ absorbance. Assays were performed in biological duplicate, each in technical triplicate. MIC value was determined at the minimum concentration of bacteriocin where no growth of L. plantarum A6 occurred.

Statistical analysis. The results of the MIC assay were analysed via a One-way ANOVA and post-hoc Tukey honestly significant difference test using the tool at https://astatsa.com/OneWay_Anova_with_Tukey HSD/_get_data/, date accessed: 17/9/20).

\section{Data availability}

The plantacyclin B21AG crystal structure coordinates and structure factors are available in the Protein Data Bank repository with a PDB code 6WI6, [https://www.rcsb.org/].

Received: 2 July 2020; Accepted: 21 September 2020

Published online: 15 October 2020

\section{References}

1. Cotter, P. D., Hill, C. \& Ross, R. P. Bacteriocins: developing innate immunity for food. Nat. Rev. Microbiol. 3, 777-788 (2005).

2. Gálvez, A., Maqueda, M., Martínez-Bueno, M. \& Valdivia, E. Permeation of bacterial cells, permeation of cytoplasmic and artificial membrane vesicles, and channel formation on lipid bilayers by peptide antibiotic AS-48. J. Bacteriol. 173, 886-892 (1991).

3. Yang, S.-C., Lin, C.-H., Sung, C. T. \& Fang, J.-Y. Antibacterial activities of bacteriocins: application in foods and pharmaceuticals. Front. Microbiol. 5, 241 (2014).

4. O'Connor, P. M., Ross, R. P., Hill, C. \& Cotter, P. D. Antimicrobial antagonists against food pathogens: a bacteriocin perspective. Curr. Opin. Food Sci. 2, 51-57 (2015).

5. Perez, R. H., Zendo, T. \& Sonomoto, K. Novel bacteriocins from lactic acid bacteria (LAB): various structures and applications. Microb. Cell Fact. 13, 1 (2014).

6. Nes, I. F., Yoon, S. \& Diep, D. B. Ribosomally synthesiszed antimicrobial peptides (bacteriocins) in lactic acid bacteria: a review. Food Sci. Biotechnol. 16, 675 (2007).

7. Acedo, J. Z., Chiorean, S., Vederas, J. C. \& van Belkum, M. J. The expanding structural variety among bacteriocins from Grampositive bacteria. FEMS Microbiol. Rev. 42, 805-828 (2018).

8. Perez, R. H., Zendo, T. \& Sonomoto, K. Circular and leaderless bacteriocins: biosynthesis, mode of action, applications and prospects. Front. Microbiol. 9, 2085 (2018).

9. van Heel, A. J., Montalban-Lopez, M., Oliveau, Q. \& Kuipers, O. P. Genome-guided identification of novel head-to-tail cyclized antimicrobial peptides, exemplified by the discovery of pumilarin. Microb. Genom. 3, e000134 (2017).

10. Vezina, B., Rehm, B. H. \& Smith, A. T. Bioinformatic prospecting and phylogenetic analysis reveals 94 undescribed circular bacteriocins and key motifs. BMC Microbiol. 20, 1-16 (2020).

11. Van Belkum, M. J., Martin-Visscher, L. A. \& Vederas, J. C. Structure and genetics of circular bacteriocins. Trends Microbiol. 19, 411-418 (2011).

12. Potter, A., Ceotto, H., Coelho, M. L. V., Guimarães, A. J. \& de Freire Bastos, M. D. C. The gene cluster of aureocyclicin 4185: the first cyclic bacteriocin of Staphylococcus aureus. Microbiology 160, 917-928 (2014).

13. Himeno, K. et al. Identification, characterization, and three-dimensional structure of the novel circular bacteriocin, enterocin NKR-5-3B, from Enterococcus faecium. Biochemistry 54, 4863-4876 (2015).

14. Scholz, R. et al. Amylocyclicin, a novel circular bacteriocin produced by Bacillus amyloliquefaciens FZB42. J. Bacteriol. 196, 1842-1852 (2014).

15. Kurata, A., Yamaguchi, T., Kira, M. \& Kishimoto, N. Characterization and heterologous expression of an antimicrobial peptide from Bacillus amyloliquefaciens CMW1. Biotechnol. Biotechnol. Equip. 33, 886-893 (2019).

16. Samyn, B. et al. The cyclic structure of the enterococcal peptide antibiotic AS-48. FEBS Lett. 352, 87-90 (1994).

17. Tomita, H., Fujimoto, S., Tanimoto, K. \& Ike, Y. Cloning and genetic and sequence analyses of the bacteriocin 21 determinant encoded on the Enterococcus faecalis pheromone-responsive conjugative plasmid pPD1. J. Bacteriol. 179, 7843-7855 (1997).

18. Martin-Visscher, L. A. et al. Isolation and characterization of carnocyclin A, a novel circular bacteriocin produced by Carnobacterium maltaromaticum UAL307. Appl. Environ. Microbiol. 74, 4756-4763 (2008).

19. Kemperman, R. et al. Identification and characterization of two novel clostridial bacteriocins, circularin A and closticin 574. Appl. Environ. Microbiol. 69, 1589-1597 (2003).

20. Egan, K. Discovery and Evaluation of Novel and Characterised Bacteriocins for Future Applications (University College Cork, Cork, 2018).

21. Borrero, J. et al. Characterization of garvicin ML, a novel circular bacteriocin produced by Lactococcus garvieae DCC43, isolated from mallard ducks (Anas platyrhynchos). Appl. Environ. Microbiol. 77, 369-373 (2011).

22. Sawa, N. et al. Identification and characterization of lactocyclicin Q, a novel cyclic bacteriocin produced by Lactococcus sp. strain QU 12. Appl. Environ. Microbiol. 75, 1552-1558 (2009). 
23. Masuda, Y. et al. Identification and characterization of leucocyclicin Q, a novel cyclic bacteriocin produced by Leuconostoc mesenteroides TK41401. Appl. Environ. Microbiol. 77, 8164-8170 (2011).

24. Wirawan, R. E., Swanson, K. M., Kleffmann, T., Jack, R. W. \& Tagg, J. R. Uberolysin: a novel cyclic bacteriocin produced by Streptococcus uberis. Microbiology 153, 1619-1630 (2007).

25. Xin, B. et al. In silico analysis highlights the diversity and novelty of circular bacteriocins in sequenced microbial genomes. Msystems 5, e00047-20 (2020)

26. Kawai, Y., Saito, T., Kitazawa, H. \& Itoh, T. Gassericin A; an uncommon cyclic bacteriocin produced by Lactobacillus gasseri LA39 linked at N-and C-terminal ends. Biosci. Biotechnol. Biochem. 62, 2438-2440 (1998).

27. Kalmokoff, M., Cyr, T., Hefford, M., Whitford, M. \& Teather, R. Butyrivibriocin AR10, a new cyclic bacteriocin produced by the ruminal anaerobe Butyrivibrio fibrisolvens AR10: characterization of the gene and peptide. Can. J. Microbiol. 49, 763-773 (2003).

28. Acedo, J. Z. et al. Solution structure of acidocin B, a circular bacteriocin produced by Lactobacillus acidophilus M46. Appl. Environ. Microbiol. 81, 2910-2918 (2015).

29. Collins, F. W. et al. Bacteriocin gene-trait matching across the complete Lactobacillus pan-genome. Sci. Rep. 7, 1-14 (2017).

30. Borrero, J. et al. Purification, characterization and heterologous production of plantaricyclin A, a novel circular bacteriocin produced by Lactobacillus plantarum NI326. Appl. Environ. Microbiol. 84, 01801-01817 (2017).

31. Golneshin, A. et al. Discovery and characterisation of circular bacteriocin plantacyclin B21AG from Lactiplantibacillus plantarum B21. Heliyon 6, e04715 (2020).

32. Golneshin, A. Characterisation of Bacteriocin Genes and Proteins from Lactobacillus plantarum B21 as Potential New Antimicrobial Agents and Natural Food Preservatives (RMIT University, 2014).

33. Golneshin, A., et al. Bacteriocin polypeptides and uses thereof. Google Patents (2016).

34. Sánchez-Barrena, M. et al. Structure of bacteriocin AS-48: from soluble state to membrane bound state. J. Mol. Biol. 334, 541-549 (2003).

35. Wang, C. K. et al. Combined X-ray and NMR analysis of the stability of the cyclotide cystine knot fold that underpins its insecticidal activity and potential use as a drug scaffold. J. Biol. Chem. 284, 10672-10683 (2009).

36. Gabrielsen, C., Brede, D. A., Nes, I. F. \& Diep, D. B. Circular bacteriocins: biosynthesis and mode of action. Appl. Environ. Microbiol. 80, 6854-6862 (2014).

37. Montalbán-López, M. et al. Characterization of linear forms of the circular enterocin AS- 48 obtained by limited proteolysis. FEBS Lett. 582, 3237-3242 (2008).

38. Sánchez-Hidalgo, M. et al. AS-48 bacteriocin: close to perfection. Cell. Mol. Life Sci. 68, 2845-2857 (2011).

39. Cobos, E. et al. AS-48: a circular protein with an extremely stable globular structure. FEBS Lett. 505, 379-382 (2001).

40. Cobos, E. S. et al. The denaturation of circular enterocin AS-48 by urea and guanidinium hydrochloride. Biochim. Biophys. Acta Proteins Proteom. 1598, 98-107 (2002).

41. Cebrián, R. et al. Insights into the functionality of the putative residues involved in enterocin AS-48 maturation. Appl. Environ. Microbiol. 76, 7268-7276 (2010).

42. Zheng, J. et al. A taxonomic note on the genus Lactobacillus: description of 23 novel genera, emended description of the genus Lactobacillus Beijerinck 1901, and union of Lactobacillaceae and Leuconostocaceae. Int. J. Syst. Evol. Microbiol. 70, 2782-2858 (2020).

43. Gor, M. C., Golneshin, A., Van, T. T. H. \& Moore, R. J. Smith AT Cloning and functional expression of a food-grade circular bacteriocin, plantacyclin B21AG, in probiotic Lactobacillus plantarum WCFS1. PLoS ONE 15, e0232806 (2020).

44. Martin-Visscher, L. A., Gong, X., Duszyk, M. \& Vederas, J. C. The three-dimensional structure of carnocyclin A reveals that many circular bacteriocins share a common structural motif. J. Biol. Chem. 284, 28674-28681 (2009).

45. Fraczkiewicz, R. \& Braun, W. Exact and efficient analytical calculation of the accessible surface areas and their gradients for macromolecules. J. Comput. Chem. 19, 319-333 (1998).

46. Towle, K. \& Vederas, J. Structural features of many circular and leaderless bacteriocins are similar to those in saposins and saposinlike peptides. Med. Chem. Commun. 8, 276-285 (2017).

47. Jiménez, M. A., Barrachi-Saccilotto, A. C., Valdivia, E., Maqueda, M. \& Rico, M. Design, NMR characterization and activity of a 21-residue peptide fragment of bacteriocin AS-48 containing its putative membrane interacting region. J. Pept. Sci. 11, 29-36 (2005).

48. Cantisani, M. et al. Structural insights into and activity analysis of the antimicrobial peptide myxinidin. Antimicrob. Agents Chemother. 58, 5280-5290 (2014).

49. Kemperman, R. A. Functional Analysis of Circular and Linear Bacteriocins of Gram-Positive Bacteria (University Library Groningen, 2005).

50. Kazazic, M., Nissen-Meyer, J. \& Fimland, G. Mutational analysis of the role of charged residues in target-cell binding, potency and specificity of the pediocin-like bacteriocin sakacin P. Microbiology 148, 2019-2027 (2002).

51. Jiang, H., Zou, J., Cheng, H., Fang, J. \& Huang, G. Purification, characterization, and mode of action of pentocin JL-1, a novel bacteriocin isolated from Lactobacillus pentosus, against drug-resistant Staphylococcus aureus. BioMed Res. Intern. 2017, 7657190. https://doi.org/10.1155/2017/7657190 (2017) (Bioactive Natural Products 2017).

52. González, C. et al. Bacteriocin AS-48, a microbial cyclic polypeptide structurally and functionally related to mammalian NK-lysin. Proc. Natl. Acad. Sci. 97, 11221-11226 (2000).

53. Gong, X., Martin-Visscher, L. A., Nahirney, D., Vederas, J. C. \& Duszyk, M. The circular bacteriocin, carnocyclin A, forms anionselective channels in lipid bilayers. Biochim. Biophys. Acta Biomembr. 1788, 1797-1803 (2009).

54. Fucile, S. The distribution of charged amino acid residues and the $\mathrm{Ca}^{2+}$ permeability of nicotinic acetylcholine receptors: a predictive model. Front. Mol. Neurosci. 10, 155 (2017).

55. Kyte, J. \& Doolittle, R. F. A simple method for displaying the hydropathic character of a protein. J. Mol. Biol. 157, 105-132 (1982).

56. Schrodinger, L. The PyMOL molecular graphics system. Version 1 (2010).

57. Drozdetskiy, A., Cole, C., Procter, J. \& Barton, G. J. JPred4: a protein secondary structure prediction server. Nucleic Acids Res. 43, W389-W394 (2015)

58. Braun, P. \& von Heijne, G. The aromatic residues Trp and Phe have different effects on the positioning of a transmembrane helix in the microsomal membrane. Biochemistry 38, 9778-9782 (1999).

59. Gleason, N. J., Greathouse, D. V., Grant, C. V., Opella, S. J. \& Koeppe, R. E. Single tryptophan and tyrosine comparisons in the $\mathrm{N}$-terminal and C-terminal interface regions of transmembrane GWALP peptides. J. Phys. Chem. B 117, 13786-13794 (2013).

60. Sanchez-Hidalgo, M. et al. Conformational stability and activity of circular enterocin AS-48 derivatives. Protein Pept. Lett. 17, 708-714 (2010).

61. Shepherd, C. M., Vogel, H. J. \& Tieleman, D. P. Interactions of the designed antimicrobial peptide MB21 and truncated dermaseptin S3 with lipid bilayers: molecular-dynamics simulations. Biochem. J. 370, 233-243 (2003).

62. Killian, J. A., Timmermans, J. W., Keur, S. \& de Kruijff, B. The tryptophans of gramicidin are essential for the lipid structure modulating effect of the peptide. Biochim. Biophys. Acta Biomembr. 820, 154-156 (1985).

63. Kelkar, D. A. \& Chattopadhyay, A. The gramicidin ion channel: a model membrane protein. Biochim. Biophys. Acta Biomembr. 1768, 2011-2025 (2007).

64. Sparks, K. A. et al. Comparisons of interfacial Phe, Tyr, and Trp residues as determinants of orientation and dynamics for GWALP transmembrane peptides. Biochemistry 53, 3637-3645 (2014). 
65. Perkins, R. \& Vaida, V. Phenylalanine increases membrane permeability. J. Am. Chem. Soc. 139, 14388-14391 (2017).

66. Aragao, D. et al. MX2: a high-flux undulator microfocus beamline serving both the chemical and macromolecular crystallography communities at the Australian Synchrotron. J. Synchrotron Radiat. 25, 885-891 (2018).

67. Kabsch, W. Integration, scaling, space-group assignment and post-refinement. Acta Crystallogr. Sect. D Biol. Crystallogr. 66, 133-144 (2010).

68. Evans, P. R. \& Murshudov, G. N. How good are my data and what is the resolution?. Acta Crystallogr. Sect. D Biol. Crystallogr. 69, 1204-1214 (2013).

69. Winn, M. D. et al. Overview of the CCP4 suite and current developments. Acta Crystallogr. Sect. D 67, 235-242 (2011).

70. McCoy, A. J. et al. Phaser crystallographic software. J. Appl. Crystallogr. 40, 658-674 (2007).

71. Sheldrick, G. M. Experimental phasing with SHELXC/D/E: combining chain tracing with density modification. Acta Crystallogr. Sect. D Biol. Crystallogr. 66, 479-485 (2010).

72. Sheldrick, G. M. A short history of SHELX. Acta Crystallogr. A 64, 112-122 (2008).

73. Thorn, A. \& Sheldrick, G. M. Extending molecular-replacement solutions with SHELXE. Acta Crystallogr. Sect. D Biol. Crystallogr. 69, 2251-2256 (2013).

74. Panjikar, S., Parthasarathy, V., Lamzin, V. S., Weiss, M. S. \& Tucker, P. A. Auto-Rickshaw: an automated crystal structure determination platform as an efficient tool for the validation of an X-ray diffraction experiment. Acta Crystallogr. Sect. D Biol. Crystallogr. 61, 449-457 (2005).

75. Panjikar, S., Parthasarathy, V., Lamzin, V. S., Weiss, M. S. \& Tucker, P. A. On the combination of molecular replacement and singlewavelength anomalous diffraction phasing for automated structure determination. Acta Crystallogr. Sect. D Biol. Crystallogr. 65, 1089-1097 (2009).

76. Brünger, A. T. et al. Crystallography \& NMR system: a new software suite for macromolecular structure determination. Acta Crystallogr. Sect. D Biol. Crystallogr. 54, 905-921 (1998).

77. Murshudov, G. N. et al. REFMAC5 for the refinement of macromolecular crystal structures. Acta Crystallogr. Sect. D Biol. Crystallogr. 67, 355-367 (2011).

78. Vagin, A. A. et al. REFMAC5 dictionary: organization of prior chemical knowledge and guidelines for its use. Acta Crystallogr. Sect. D Biol. Crystallogr. 60, 2184-2195 (2004).

79. Cowtan, K. General quadratic functions in real and reciprocal space and their application to likelihood phasing. Acta Crystallogr. Sect. D Biol. Crystallogr. 56, 1612-1621 (2000).

80. Langer, G., Cohen, S. X., Lamzin, V. S. \& Perrakis, A. Automated macromolecular model building for X-ray crystallography using ARP/wARP version 7. Nat. Protoc. 3, 1171 (2008).

81. Berman, H., Henrick, K. \& Nakamura, H. Announcing the worldwide protein data bank. Nat. Struct. Mol. Biol. 10, 980-980 (2003).

82. Young, J. Y. et al. OneDep: unified wwPDB system for deposition, biocuration, and validation of macromolecular structures in the PDB archive. Structure 25, 536-545 (2017).

83. Emsley, P. \& Cowtan, K. Coot: model-building tools for molecular graphics. Acta Crystallogr. Sect. D Biol. Crystallogr. 60, 2126-2132 (2004).

84. Baker, N. A., Sept, D., Joseph, S., Holst, M. J. \& McCammon, J. A. Electrostatics of nanosystems: application to microtubules and the ribosome. Proc. Natl. Acad. Sci. 98, 10037-10041 (2001).

85. Dolinsky, T. J., Nielsen, J. E., McCammon, J. A. \& Baker, N. A. PDB2PQR: an automated pipeline for the setup of Poisson-Boltzmann electrostatics calculations. Nucleic Acids Res. 32, W665-W667 (2004).

86. Pettersen, E. F. et al. UCSF Chimera-a visualization system for exploratory research and analysis. J. Comput. Chem. 25, 1605-1612 (2004).

87. Madeira, F. et al. The EMBL-EBI search and sequence analysis tools APIs in 2019. Nucleic Acids Res. 47, W636-W641 (2019).

88. Stamatakis, A. RAxML version 8: a tool for phylogenetic analysis and post-analysis of large phylogenies. Bioinformatics 30, 13121313 (2014).

89. Golneshin, A. et al. Complete genome sequence of Lactobacillus plantarum strain B21, a bacteriocin-producing strain isolated from Vietnamese fermented sausage nem chua. Genome Announc. 3, e00055-e15 (2015).

90. Yang, P., Wang, J. \& Qi, Q. Prophage recombinases-mediated genome engineering in Lactobacillus plantarum. Microb. Cell Fact. 14, 154 (2015).

91. Gill, S. C. \& Von Hippel, P. H. Calculation of protein extinction coefficients from amino acid sequence data. Anal. Biochem. 182, 319-326 (1989).

92. Golneshin, A. et al. Draft genome sequence of Lactobacillus plantarum strain A6, a strong acid producer isolated from a Vietnamese fermented sausage (Nem Chua). Genome Announc. 5, e00987-17 (2017).

93. Tran, K. T.-M. Investigation of the Native Microflora and Isolation of Protective Starter Culture for a Traditional Vietnamese Fermented Meat (RMIT University, 2010).

\section{Acknowledgements}

This study was supported by Griffith University Postdoctoral Fellowships. We thank Karl Byriel, the manager of the University of Queensland Remote Operation Crystallization and X-ray Diffraction Facility (UQROCX) that we accessed for protein crystallization, crystal imaging and X-ray diffraction. We thank the University of Queensland Institute for Molecular Bioscience's (IMB) Mass Spectrometry Facility for access to MALDI-TOFMS. This research was undertaken in part using the MX2 beamline at the Australian Synchrotron, ANSTO and made use of the Australian Cancer Research Foundation (ACRF) detector and we are grateful for access to the Synchrotron, for data collection and processing.

\section{Author contributions}

A.T.S., J.L.M., M.C.G., B.R. and B.V conceived and designed the experiment(s); M.C.G., B.V., R.M.M. and G.K. conducted the experiment(s), S.P., M.C.G. and B.V. analysed the data. J.L.M. provided access to instrumentation at Griffith University. M.C.G and B.V. wrote the main manuscript text. All authors reviewed the manuscript.

\section{Competing interests}

The authors declare no competing interests.

\section{Additional information}

Supplementary information is available for this paper at https://doi.org/10.1038/s41598-020-74332-1.

Correspondence and requests for materials should be addressed to A.T.S. 
Reprints and permissions information is available at www.nature.com/reprints.

Publisher's note Springer Nature remains neutral with regard to jurisdictional claims in published maps and institutional affiliations.

(c) (i) Open Access This article is licensed under a Creative Commons Attribution 4.0 International License, which permits use, sharing, adaptation, distribution and reproduction in any medium or format, as long as you give appropriate credit to the original author(s) and the source, provide a link to the Creative Commons licence, and indicate if changes were made. The images or other third party material in this article are included in the article's Creative Commons licence, unless indicated otherwise in a credit line to the material. If material is not included in the article's Creative Commons licence and your intended use is not permitted by statutory regulation or exceeds the permitted use, you will need to obtain permission directly from the copyright holder. To view a copy of this licence, visit http://creativecommons.org/licenses/by/4.0/.

(C) The Author(s) 2020 